\title{
Dibutyryl Cyclic AMP Induces Vimentin and GFAP Expression in Cultured Medulloblastoma Cells
}

\author{
B.L. Maria, D. Wong and V.I. Kalnins
}

\begin{abstract}
Evidence for the astrocytic lineage in medulloblastomas rests largely on the detection of the glial fibrillary acidic protein (GFAP) from which intermediate filaments (IF) specific for astrocytes are assembled. Astrocyte progenitor cells from the mouse neopallium however express another IF protein, vimentin, before they acquire GFAP in vivo and in vitro. The purpose of the current study was to determine if cells obtained from a focally GFAP-positive posterior fossa medulloblastoma previously shown to acquire GFAP in response to dibutyryl cyclic AMP (dBcAMP), also express vimentin before expressing GFAP. More than $80 \%$ of cells in the tumor section contained vimentin while fewer than $1 \%$ of cells contained GFAP; occasional clusters of malignant GFAP-positive cells and clusters of cells negative for both vimentin and GFAP were also identified in the tumor. One hundred per cent of cultured cells in the first 10 passages from the tumor contained vimentin and no cells expressed GFAP. When cells were cultured in the presence of dBcAMP, Western immunoblotting showed an increase in vimentin which reached maximal values within $24 \mathrm{~h}$ followed by an increase in GFAP which reached maximal values at $72 \mathrm{~h}$. The increase in vimentin followed by that of GFAP in cultured medulloblastoma cells has not previously been reported and suggests that most astrocyte progenitors which are derived from medulloblastoma and cultured in vitro may be at a developmental stage which corresponds to the proastroblast stage in the developing mouse brain. Most medulloblastoma cells in tumor sections in which vimentin is present but GFAP is absent may be in maturation arrest in vivo at the proastroblast stage of normal astrocyte development while vimentin and GFAP-negative islands of cells may represent astrocyte progenitor cells at an earlier stage of differentiation (e.g. glioblasts).
\end{abstract}

\begin{abstract}
RÉSUMÉ: L'amp cyclique dibutyryl induit l'expression de la vimentine et de la GFAP dans des cellules de médulloblastome en culture L'évaluation de la lignée cellulaire dans le médulloblastome repose sur l'identification de la protéine gliale acide (GFAP) et est limitée par le fait que peu de marqueurs de cellules astrocytaires immatures sont disponibles. Les cellules progénitrices astrocytaires obtenues du neopallium de la souris contiennent les filaments intermédiaires type-vimentine avant d'exprimer la GFAP autant in vivo qu'in vitro. Notre étude avait pour but de déterminer si des cellules de la lignée astrocytaire en culture obtenues d'un médulloblastome avec différenciation astrocytaire contenaient la vimentine et si elle était aussi présente dans les cellules malignes GFAP-negatives de la section histologique. Plus de $80 \%$ des cellules de la section histologique de la tumeur étaient positives pour la vimentine alors que moins de $1 \%$ des cellules de la tumeur contenaient la GFAP; quelques îlots de cellules malignes ne contenaient ni la vimentine ni la GFAP. Suivant le traitement des cellules en culture avec le AMP cyclique dibutyryl (dBcAMP), l'analyse Western des proteines a démontré une induction de la vimentine en dedans de $24 \mathrm{~h}$ suivie d'une induction maximale de la GFAP à 72 h. Cette séquence d'induction de la vimentine et de la GFAP par le dBcAMP dans les cellules gliales n'a pas été rapporté dans le passé et suggère que les cellules gliales progénitrices qui sont dérivées du médulloblastome en question et cultivées in vitro pourraient être à un stade qui correspond au stade pro-astroblaste dans le dévelopment du cerveau de souris. Les sections histologiques de cellules du médulloblastome qui contiennent la vimentine mais non la GFAP pourraient aussi être en arrêt de maturation in vivo au stade pro-astroblaste. Les îlots de cellules dans le médulloblastome qui ne contiennent ni la vimentine ni la GFAP pourraient représenter des cellules astrocytaires progénitrices à un stade encore plus précoce de différenciation tel que les glioblastes.
\end{abstract}

Can.J. Neurol. Sci. 1990; 17: 15-20

From the Department of Pediatrics, (Divisions of Neurology (B.L.M., D.W.) and Haematology/Oncology (B.L.M.), The Hospital for Sick Children and the Department of Anatomy (V.I.K.), University of Toronto, Toronto

Received May 2, 1989. Accepted in final form September 25, 1989

Reprint requests to: Dr. B.L. Maria, Division of Neurology, The Hospital for Sick Children, 555 University Avenue, Toronto, Ontario, Canada M5G 1X8 
Medulloblastoma is the most common primitive neuroectodermal tumor (PNET) in the central nervous system. It constitutes up to 25 per cent of brain tumors in childhood. 1,2 Microscopically, medulloblastomas are primarily composed of sheets of uniform, small malignant cells and may or may not have features typical of astrocytic or neuronal cells. ${ }^{3}$ The evidence for astrocytic lineage in medulloblastoma is provided by the presence of an immunological marker of mature astrocytes, the glial fibrillary acidic protein (GFAP). GFAP is an astrocyte specific intermediate filament (IF) protein present in normal differentiated astrocytes, in large reactive astrocytes that appear after injury to the brain and in neoplastic astrocytes. During normal differentiation, the appearance of GFAP is preceded by another IF protein, vimentin. Although medulloblastomas can contain scattered GFAP positive cells with dark nuclei and indistinct cytoplasm, it is still not known whether the great majority of adjacent GFAP-negative neoplastic cells represent committed astrocytic progenitors.

The culturing of astrocyte progenitor cells derived from the mouse neopallium has provided morphological and antigenic markers for immature astrocytes at different stages in the astrocyte differentiation sequence, the glioblast, the proastroblast, the astroblast and the astrocyte. 4.5 With differentiation, nonmotile glioblasts transform into flat and motile proastroblasts and astroblasts. Astroblasts then transform further into fibrous astrocytes which are stationary and extend fine cytoplasmic processes. Glioblasts contain neither the vimentin- nor the GFAPtype IF. During differentiation, glioblasts first acquire vimentin to become proastroblasts and these cells in turn later acquire GFAP to become astroblasts. Both IF proteins persist as astroblasts acquire long processes and other characteristics of astrocytes.

We have previously shown that cultured cells derived from a medulloblastoma with astrocytic differentiation and treated with dibutyryl cyclic AMP (dBcAMP) acquire fine cytoplasmic processes and GFAP-type IF. The purpose of the current study was to reexamine histological sections and differentiating cultured cells from this medulloblastoma for the presence of vimentintype IF and to compare this expression with that of GFAP. 6 The results indicate that most cells in medulloblastoma and in cultures derived from medulloblastoma are vimentin-positive but GFAP-negative and therefore are at a stage which corresponds to the proastroblast stage in the newborn mouse neopallium. The vimentin and GFAP-negative islands of cells seen in medulloblastomas may represent astrocyte progenitors cells at an earlier stage of differentiation such as glioblasts.

\section{Methods AND Materials}

An 8-month-old boy developed symptoms and signs of increased intracranial pressure. A posterior fossa cerebellar medulloblastoma was diagnosed and gross total resection performed. Postoperatively he was treated with nitrogen mustard, vincristine, prednisone, and procarbazine (MOPP), but 2 months later the tumor recurred locally and a tumor-debulking operation was performed.

\section{Establishment of Medulloblastoma Cell Line}

The primary and recurrent tumors were transferred to culture medium containing $20 \%$ fetal bovine serum (FBS). The specimens were finely minced and passed through a 20 -gauge needle three to five times to a single-cell suspension. The cell suspensions were plated into $100-\mathrm{mm}$ Petri dishes with Dulbecco modified Eagles/Ham's F12 medium (DMEM/F12) in a 1:1 ratio, without antibiotics but enriched with $20 \%$ FBS. The cells were incubated at $37^{\circ} \mathrm{C}$ in $5 \% \mathrm{CO}^{2}$ and grown into a semiconfluent monolayer cultures, at which time they were subcultured (RBI and RB2 cells). The culture medium (DMEM/F12 enriched with $10 \%$ FBS) was changed twice weekly. The population-doubling time of RB2 cells, colony-forming efficiency in soft agar, and chromosomal analysis with $\mathrm{G}, \mathrm{Q}$ and $\mathrm{C}$ bandings were previously described. ${ }^{6}$ No differences in cell morphology were noted between the RB1 and RB2 cultures for the first 10 cultured passages. Thereafter, RB1 cells failed to become established while RB2 cells maintained their population-doubling time and morphology. Hence, RB2 cells were selected for further study.

\section{Culture of RB2 Cells}

RB2 cells from the first 10 cultured passages were stored at $-150^{\circ} \mathrm{C}$. Frozen cells from a given passage were quickly thawed for the cell culture experiments. Reconstituted dBcAMP (Sigma, St. Louis, MO) was stored in DMEM/F12 at $-20^{\circ} \mathrm{C}$. Every 3 days, fresh medium containing $\operatorname{dBcAMP}(2 \mathrm{mM})$ was added to each appropriate culture dish; control wells contained fresh medium alone.

\section{Immunohistochemistry}

\section{a) Tumor Sections}

Immunohistochemical study of the medulloblastoma surgical specimen was performed with rabbit polyclonal antibodies to GFAP (1:1000) and mouse monoclonal antibodies to vimentin (1:1000) (Dako Corp., Santa Barbara, CA). The medulloblastoma tissue section was also examined for the presence of neurofilament protein $(200 \mathrm{kD})$, desmin, myoglobin and neuronspecific enolase with antibodies specific for these proteins (Dako Corp., Santa Barbara, CA). Formalin-fixed, paraffinembedded tissue sections treated with the above antibodies were immunohisto chemically stained using the peroxidase anti-peroxidase (PAP) method of Sternberger. ${ }^{7}$

\section{b) Cell Cultures}

For immunohistochemical characterization of cultured cells, approximately $2 \times 10^{6}$ cells $/ \mathrm{ml}(50 \mu \mathrm{l}) \mathrm{RB} 2$ cells were obtained by trypsinization of cell culture dishes and were placed in culture medium on glass coverslips and incubated in medium containing $\mathrm{dBcAMP}$ for various periods of time. The coverslips were washed in phosphate-buffered saline (PBS), acetone-fixed for $5 \mathrm{~min}$, and stored frozen at $-80^{\circ} \mathrm{C}$ for no more than a week. Before staining, the slides were removed from the freezer and air-dried at $25^{\circ} \mathrm{C}$. The vimentin or GFAP antibodies or control serum diluted in PBS were incubated with RB2 cells treated with $\mathrm{dBcAMP}$ and control cells on the appropriate coverslips. All coverslips were then stained using the PAP method and examined in a Leitz Photomicroscope equipped with planachromatic objectives. The U251-MG human glioma cell line (gift of Dr. D. Bigner, Durham, NC) was used as a positive control for GFAP staining, while cultured human skin fibroblasts from $\mathrm{RB}(\mathrm{RBF})$ and cultured human lung fibroblasts from a 25 week gestational age infant (gift of Dr. H. Kirpalani, Toronto, $\mathrm{ON}$ ) were used as positive controls for the vimentin staining. The A549 human lung carcinoma cell line and TE 671 human medulloblastoma cell line which contain vimentin and the HT- 
1080 human fibrosarcoma cell line which is negative for vimentin were also obtained for study (American Type Culture Collection, Rockville, MD). The cultured human lung fibroblasts, TE 671 cells and A549 cells were examined for the presence and amount of vimentin before and after $\mathrm{ABCAMP}$ treatment.

\section{Immunoblotting}

For immunoblotting, cultured cells were washed with PBS. A cell solubilizer $(10 \mathrm{mM}$ tris HCL buffer $\mathrm{pH} 7.2,0.5 \%$ nonidet 40, $0.25 \mathrm{M}$ sucrose, $2 \mathrm{mM}$ ethyleneidiamine tetraacetic acid) and proteinase inhibitors $(2 \mathrm{mM}$ phenylmethylsulfonylfluoride, $10 \mathrm{mg} / \mathrm{ml}$ leupeptin, $10 \mathrm{mg} / \mathrm{ml}$ aprotinin) were added to the dBcAMP-treated cells and the control cells scraped from tissueculture dishes. The soluble whole cell extracts and $0.1 \%$ SDSsoluble cytoskeletal fractions were collected as previously described. ${ }^{8,9}$ For immunoblotting, equal aliquots $(100 \mu \mathrm{g})$ of both types of extracts (soluble and SDS-soluble) were separated overnight by sodium dodecyl sulfate-PAGE on a 5\% to $15 \%$ gradient gel. The proteins were then electroblotted from the gel onto $0.2 \mu \mathrm{m}$ nitrocellulose and placed overnight in PBS containing $1 \mathrm{M}$ Tris $\mathrm{HCl}, 2 \mathrm{M}$ sodium chloride, $4 \%$ polysorbate 80 (Tween 20 ), and $0.2 \%$ sodium azide, $\mathrm{pH} 7.6$. The appropriate antibody (anti-GFAP or anti-vimentin) was added, and the samples were incubated at room temperature for $1 \mathrm{~h}$ while slowly shaking. The nitrocellulose was washed in PBS, and then incubated at $25^{\circ} \mathrm{C}$ for $\mathrm{I} \mathrm{h}$ in biotinylated sheep anti-mouse IgG antibody. Labeling was detected using the Vectastain-ABC kit (Vector, Burlingame, CA) according to the manufacturer's instructions.

\section{Results}

The medulloblastoma surgical specimen from the patient's cerebellar tumor was composed of sheets of small cells with scant cytoplasm. Routine hematoxylin and eosin stain provided no evidence of differentiation. Immunohistochemical studies with antibodies to GFAP showed that fewer than $1 \%$ of malignant-appearing cells which either formed small clusters (Figure 1) or were more evenly scattered throughout the specimen were positive. No enlarged, process-bearing reactive astrocytes were detected in the tumor. In contrast, over $80 \%$ of cells (Figure 2) were positive for vimentin. Occasional clusters of cells in the tumor specimen were both negative for vimentin and GFAP. Neurofilament protein $(200 \mathrm{kd})$, desmin, myoglobin and neuron-specific enolase could not be detected. Histopathological and immunohistochemical studies of the medulloblastoma tumor specimen from the initial presentation at the age of 8 months showed the same features as the recurrent tumor described above (data not shown).

RB2 cells cultured in the presence of dBcAMP began to extend cytoplasmic processes. Examination of cultured RB2 cells in the ninth passage treated for 24,48 and $72 \mathrm{~h}$ with $\mathrm{dBcAMP}$ and controls showed that all of the treated and untreated cells expressed cytoplasmic vimentin, whereas the number of cells staining for GFAP increased from 0 per cent initially to 27 per cent after $72 \mathrm{~h}$ treatment with dBcAMP. Positive cytoplasmic staining for GFAP (Figure 3) and vimentin in the dBcAMP treated cells was seen in the cell body and processes of most process-bearing cells and throughout the cytoplasm of a few large flat cells.

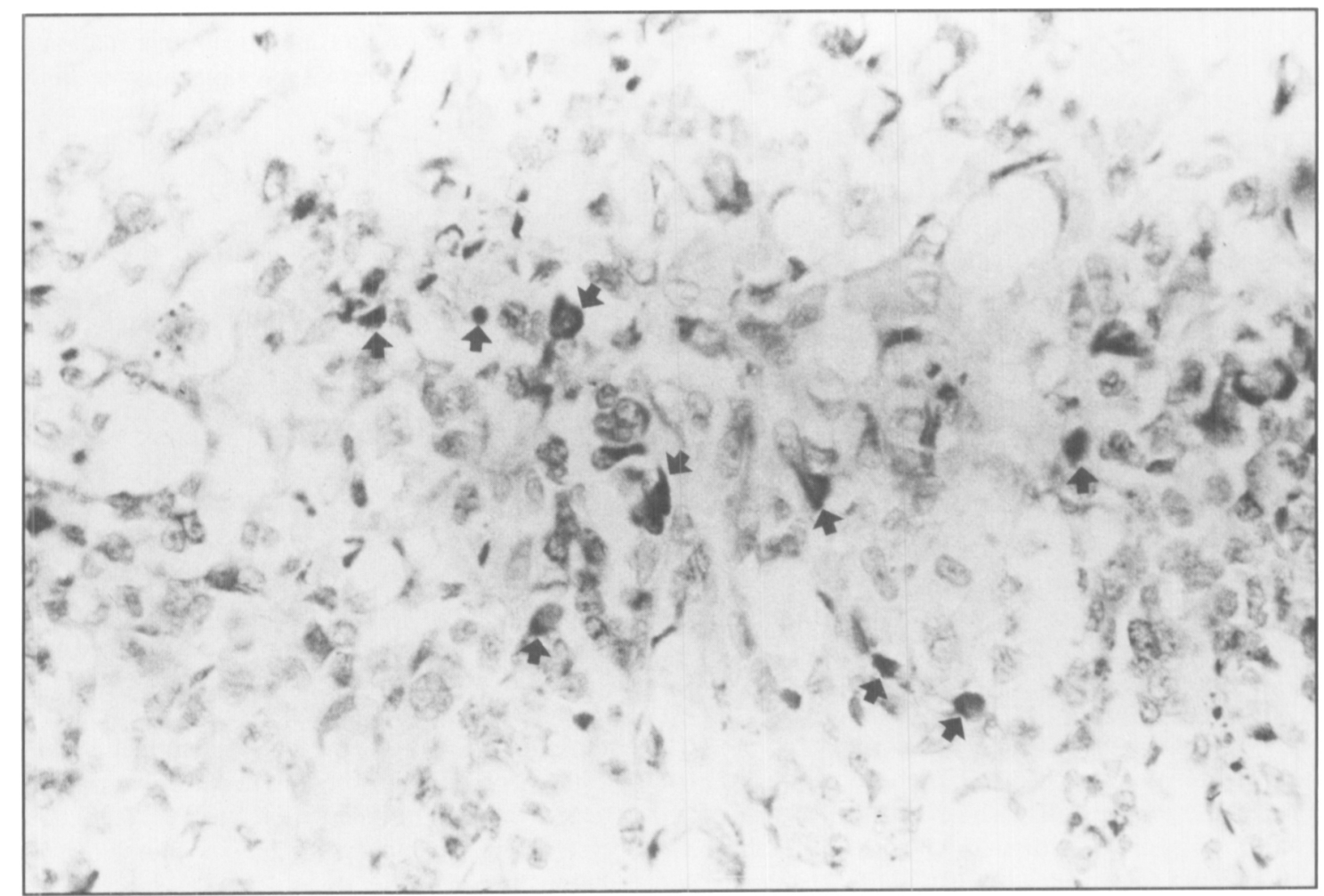

Figure I - Immunostaining of medulloblastoma for GFAP-type intermediate filaments. Scattered neoplastic cells in this section show distinct cytoplasmic reactivity with anti-GFAP (arrows). Peroxidase anti-peroxidase with hematoxylin counterstain. $\times 250$ 


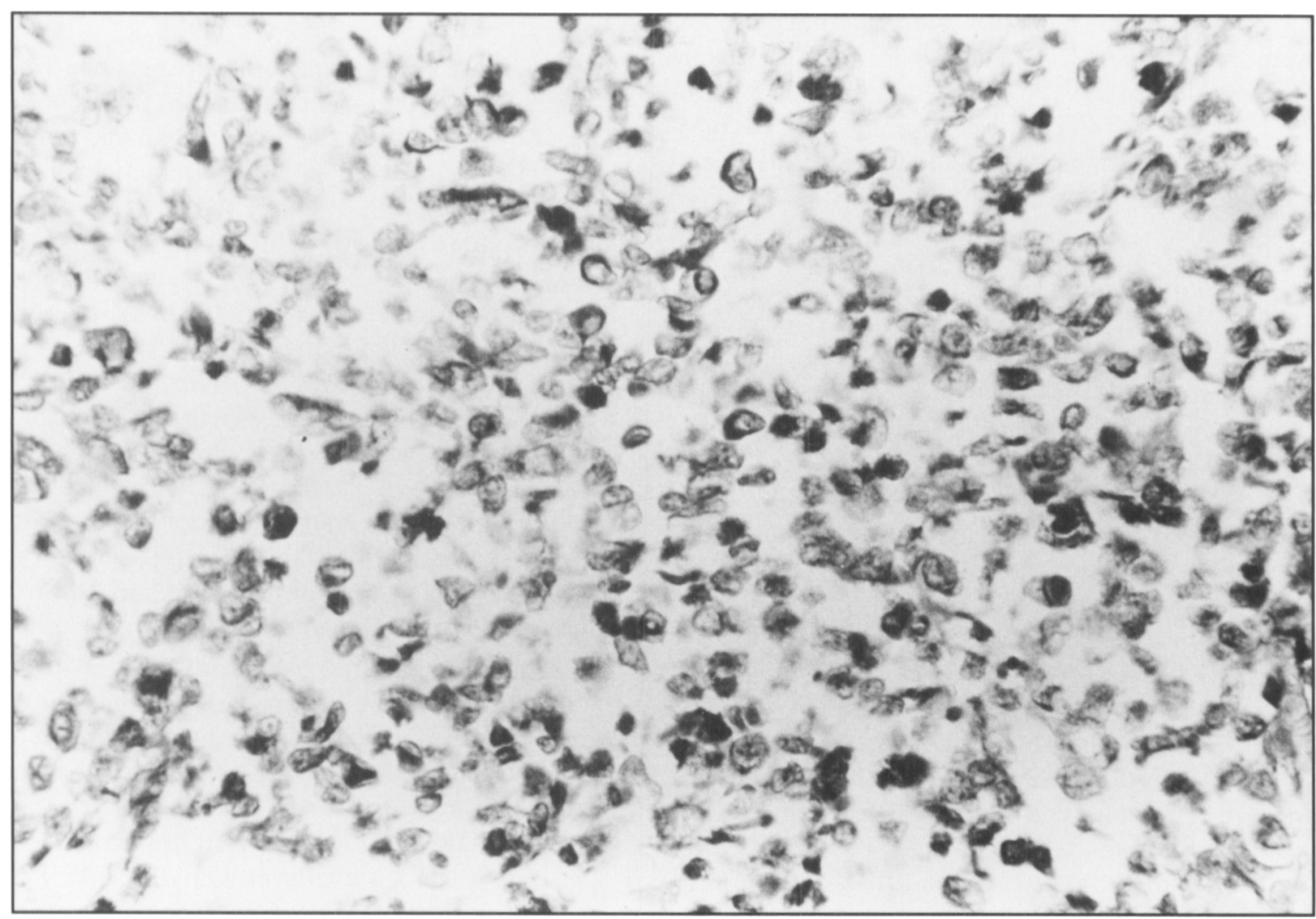

Figure 2 - Immunostaining of medulloblastoma for vimentin-type intermediate filaments. The great majority of neoplastic cells in this section show distinct cytoplasmic reactivity with anti-vimentin. Peroxidase anti-peroxidase with hematoxylin counterstain $\times 250$

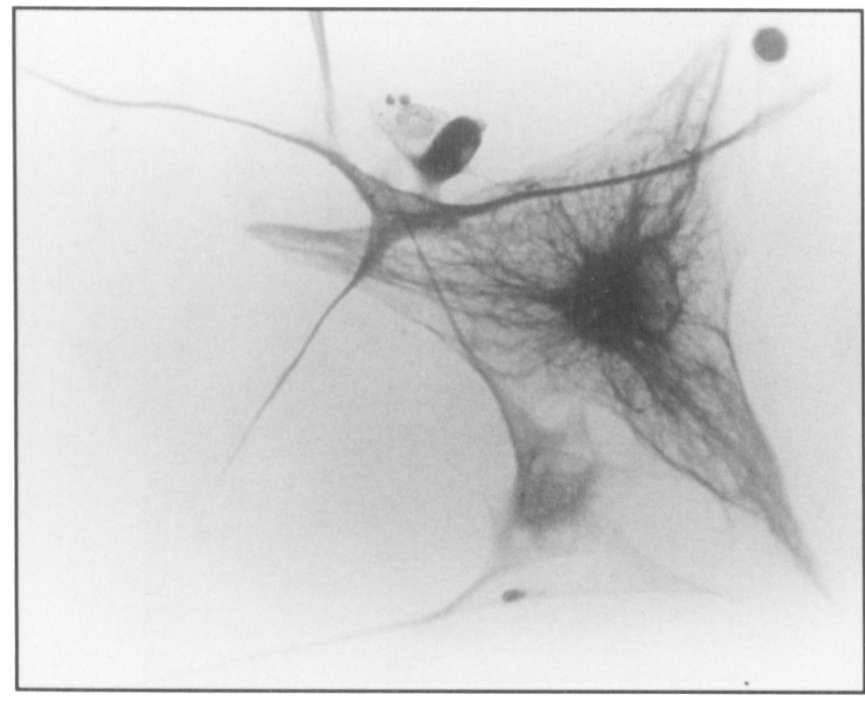

Figure 3 - Micrograph shows GFAP-type intermediare filaments in cultured RB2 cells treated with $d B C A M P\left(2 \times 10^{-3} \mathrm{M} 72 \mathrm{~h}\right)$. Note the diffuse cytoplasmic staining in process-bearing cells and in large flat cells.

Immunoblotting of untreated RB2 whole cell extracts obtained by nonidet 40 treatment showed the presence of a vimentin band (Figure 4) while GFAP was undetectable (Figure 5). Following treatment with $\mathrm{dBcAMP}$, an increase in the amount of vimentin and GFAP could be detected. Moreover, the amount of vimentin was greatest after $24 \mathrm{~h}$ of dBcAMP treatment, whereas the amount of GFAP was greatest after $72 \mathrm{~h}$ of treatment. The amount of vimentin and GFAP in RB2 cells therefore increased during phenotypic maturation induced by $\mathrm{dBcAMP}$ with the increase in vimentin preceding the increase in GFAP. The SDS-soluble cytoskeletal fractions showed a similar increase in the amount of vimentin and GFAP as the nonidet 40 cell extracts (data not shown) described above. DBcAMP has previously been shown to induce neuronal process formation in TE 671 medulloblastoma cells ${ }^{10}$ but it did not increase the amount of vimentin or GFAP as observed in RB2 cells (Figure 6); moreover, no detectable difference in the amount of vimentin was observed in the A549 lung carcinoma cell line and in the cultured lung fibroblasts treated with $\mathrm{dBcAMP}$.

\section{Discussion}

The results reported in this paper imply that vimentin-positive but GFAP-negative astrocyte progenitor cells in culture which are derived from a medulloblastoma tumor specimen with glial differentiation are at a stage which corresponds to the proastroblast stage in cultured cells derived from the newborn mouse neopallium. The great majority of malignant cells in the tumor specimen which contain vimentin but no GFAP may also be similar to proastroblasts while vimentin and GFAP-negative islands of cells may represent astrocyte progenitor cells at an earlier stage of differentiation (stem cells or glioblasts).

Although one must be cautious in drawing conclusions about the nature of cells in vivo from experiments in vitro, it seems probable that the process of differentiation from glioblasts to mature astrocytes in tissue culture models has provided information on the astrocyte cell lineage in vivo. Astrocyte progenitor 


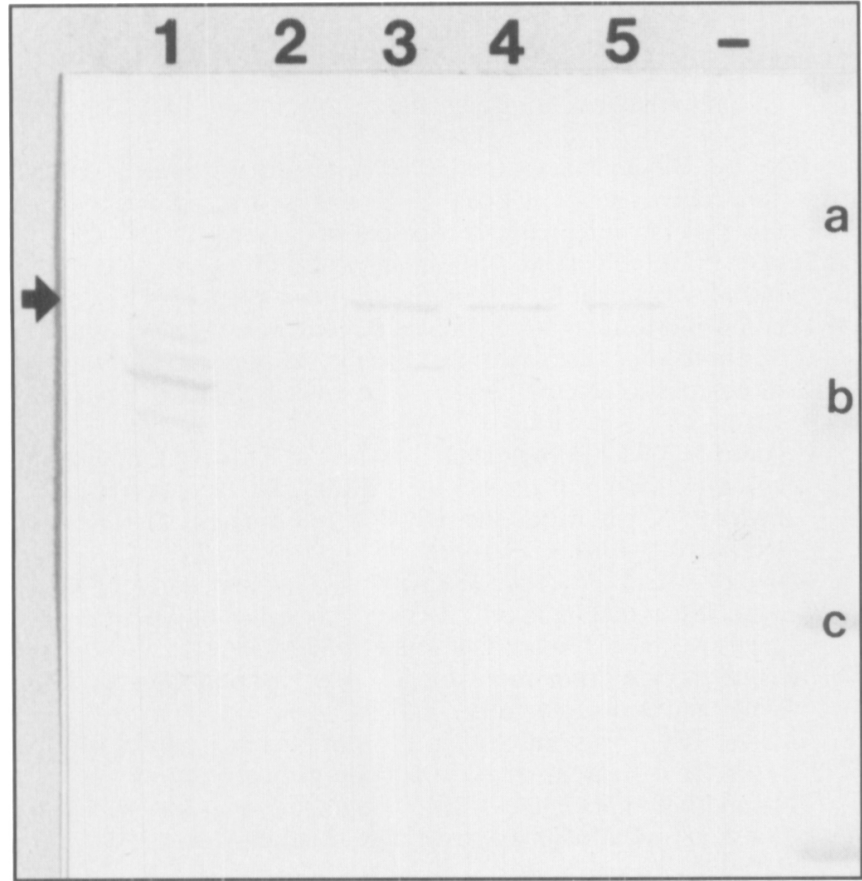

Figure 4 - Western immunoblot with the vimentin antibody of cultured $R B 2$ cells in the sixth passage. Note the presence of a vimentin epitope (58 kilodaltons) in untreated RB2 cells (lane 2). After $d B C A M P$ treatment $\left(2 \times 10^{-3} \mathrm{M}\right)$ of $24 \mathrm{~h}$ (lane 3$)$ the intensity of the vimentin band (arrow) has increased and remains visible at $48 \mathrm{~h}$ (lane 4) and $72 \mathrm{~h}$ (lane 5). Positive controls are cultured skin fibroblasts (lane l). The HT-1080 cell line is negative (-) for vimentin. Prestained molecular weight standards are (a) 68,000 (b) 43,000 (c) 29,000.

cells obtained from the RB2 medulloblastoma can be grown in monolayer cultures and differentiate in response to treatment with $\mathrm{dBcAMP}$. As in cells along the astrocytic lineage of differentiation in the mouse colony culture system, the RB2 cells express vimentin before they acquire GFAP. Previously an increase in the expression of vimentin during cell differentiation has been induced by a number of differentiating agents but not by dBcAMP. ${ }^{10}$ RB2 cells contain more vimentin following $\mathrm{dBcAMP}$ treatment and later acquire GFAP while other cultured cells which also express vimentin are not induced by $\mathrm{dBcAMP}$. The TE 671 medulloblastoma cell line is of the neuronal lineage but does not express greater amounts of vimentin following dBcAMP-induced maturation. " Unlike TE 671 cells, dBcAMP does not induce phenotypic maturation of A549 cells or cultured lung fibroblasts. However, as with TE 671, neither A549 cells nor cultured lung fibroblasts contain more vimentin-type intermediate filaments following treatment with dBcAMP. The presence of vimentin-type IF in cultured RB2 cells suggests that they are at a specific stage in the differentiation along the astrocytic lineage.

The frequency and extent of differentiation in the medulloblastoma cells as determined by morphological assessment in histological sections (including electron microscopy) has been difficult to establish, particularly without the use of specific reagents for immunohistochemistry. Immunological detection of GFAP in medulloblastoma has improved our ability to identify astrocytes in a high proportion of tumors but it is often difficult to determine if positively staining cells are normal or reactive astrocytes or neoplastic cells along the astrocytic lineage. The

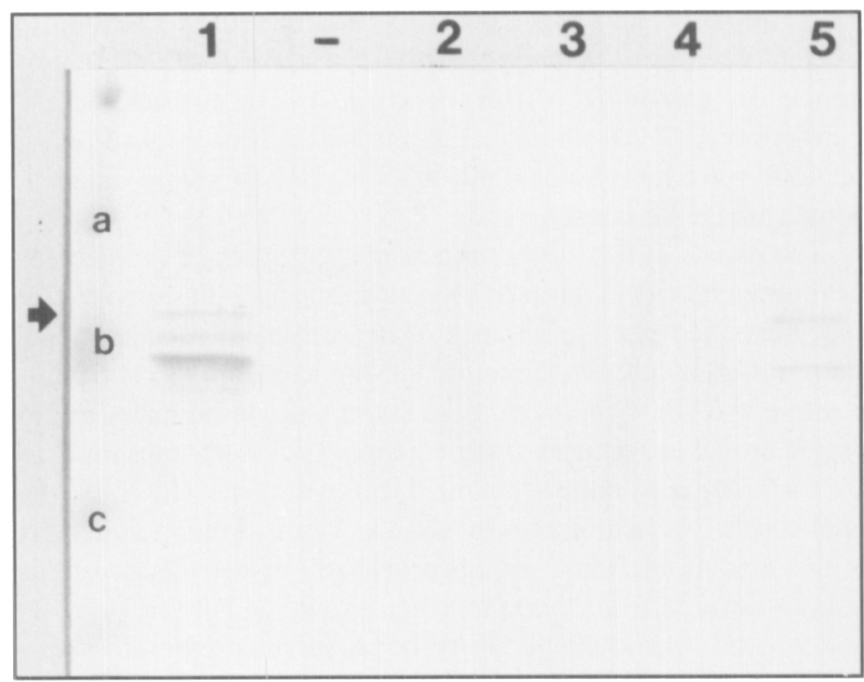

Figure 5 - Western immumoblot with the GFAP antibody of RB2 cells in the sixth passage. Note the increase in the intensity of staining and number of visible GFAP bands in RB2 cells ireated with dBcAMP $\left(2 \times 10^{-3} \mathrm{M}\right)$ for 72 h (lane 5$)$ relative to untreated $R B$ ? cells (lane 2). There is also a fain GFAP band (arrow, 47 kilodaltons) in RB2 cells treated with dBcAMP for 24 h (lame 3) and 48 h (lane 4). The U25I MG cell line (lane I) is positive for GFAP. whereas the cultured skin fibroblasts are negative (-) for GFAP. Prestained molecular weight standards are (a) 68,000 (b) 43,000 (c) 29,000 .

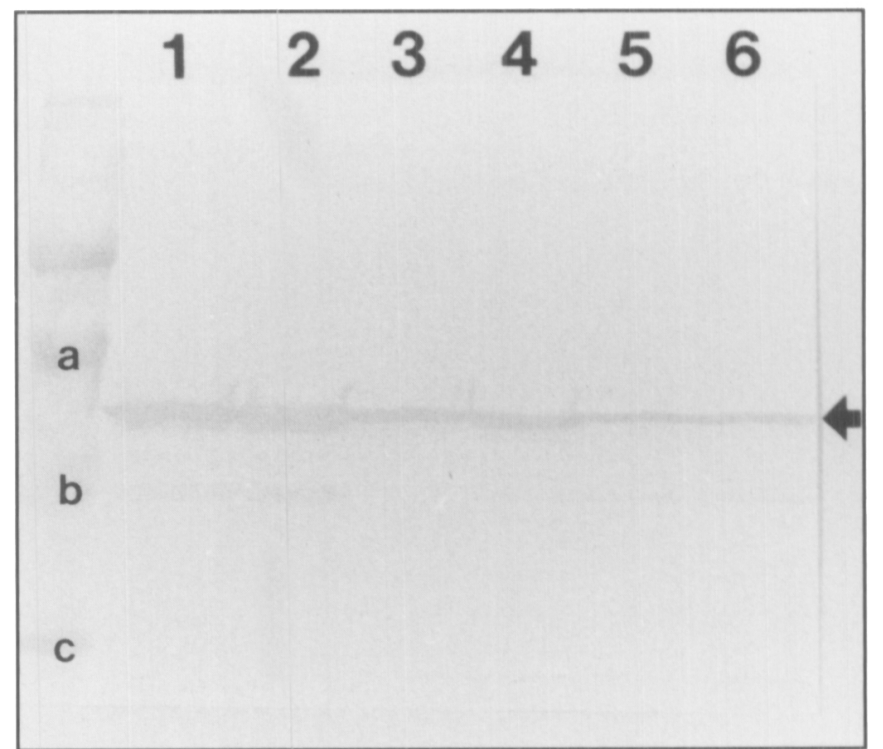

Figure 6-Western immunoblot of SDS-soluble cyroskeletal fractions from cultured human lung fibroblasts, A549 lung carcinoma cells and TE $67 \mathrm{I}$ medulloblastoma cells examined for the presence of vimentin before (lanes $I, 3$ and 5 respectively) and after (lanes 2, 4 and 6 respectively) $d B C A M P$ treatment $\left(2 \times 10^{-3} \mathrm{M}, 24 \mathrm{~h}\right)$. Note that dBcAMP does not induce an increase in vimentin staining in these cell lines. Prestained molecular weight standards are (a) 68,000 (b) 43,000 (c) 29,000 . 
observation by others that medulloblastoma cells metastatic to the leptomeninges or bone marrow can express GFAP is evidence for astrocytic differentiation by the tumor cells. ${ }^{12}$ Furthermore, GFAP staining cells in the RB2 histological tumor sections were morphologically indistinguishable from adjacent neoplastic GFAP-negative cells.

The results of this study suggest that vimentin-positive astrocyte progenitor cells may be present in medulloblastoma tumor specimens. Despite the absence of neuronal features and markers of differentiation in the tumor specimen examined, vimentinpositive and GFAP-negative cells could still theoretically represent neuronal progenitors since vimentin is present transiently in the early stages of normal neuronal differentiation. However, the total absence of neuronal immunohistochemical markers in cells of this medulloblastoma and (as previously reported) ${ }^{6}$ as well as in cells derived from this tumor and grown in culture suggests that vimentin-positive and GFAP-negative cells represent astrocyte rather than neuronal progenitors. One possible problem in interpreting the relationship between the GFAP-negative cells in tumor specimens and similar cells in vitro comes from the selection through differences in plating efficiency and culture conditions of particular cell types which may not be representative of the tumor as a whole. Cultured GFAP-negative astrocyte progenitor cells could still in theory represent the neoplastic GFAPpositive cells from the tumor specimens which have transiently lost their ability to express GFAP in vitro (prior to $\mathrm{dBcAMP}$ treatment) rather than the neoplastic vimentin-positive and GFAP-negative cells detected in the tumor. In our opinion, it seems more likely that cultured astroglia at different stages of differentiation are representative of cells along the astrocytic lineage in medulloblastoma. Hence, further experimentation in vitro may provide us with a greater understanding of maturation arrest and how it can be overcome in these medulloblastomas.

\section{ACKNOWLEDGEMENTS}

The authors thank Dr. Larry Becker for his help with these studies. Supported in part by the Research Institute, the Hospital for Sick Children and the Brain Research Fund Foundation.

\section{REFERENCES}

1. Park TS, Hoffman HJ, Hendrick EB, et al. Medulloblastoma: clinical presentation and management. J Neurosurg 1983; 58: $543-$ 552.

2. Allen JC, Bloom J, Ertel l, et al. Brain tumors in children: current cooperative and institutional chemotherapy trials in newly diagnosed and recurrent disease. Semin Oncol 1986; 13:110-122.

3. Burger PC, Grahman FC, Bliestle A, et al. Differentiation in the medulloblastoma. Acta Neuropathol (Berl) 1987; 73: 115-123.

4. Fedoroff S, McAuley WAJ, Houle JD, et al. Astrocyte cell lineage. V. Similarity of astrocytes that form in the presence of dBcAMP in cultures to reactive astrocytes in vivo. J Neurosci Res 1984; 12: $15-27$.

5. Fedoroff S, White R, Subrahmanyan L, et al. Putative astrocytes in colony cultures of mouse neopallium. In: Acosta Vidrio $\mathrm{E}$, Fedoroff S, eds. Glial and neuronal cell biology. Alan R. Liss (New York), 1981; 1:19.

6. Maria BL, Steck PA, Yung WKA, et al. The modulation of astrocytic differentiation in cells derived from a medulloblastoma surgical specimen. J Neuro-Onc 1989; 7: 329-338.

7. Sternberger LA. Immunohistochemistry. Second edition. John Wiley and Sons (New York), 1979.

8. Burnette WN. "Western blotting": electrophoretic transfer of proteins from sodium dodecyl sulfate-polyacrylamide gels to unmodified nitrocellulose and radiographic detection with antibody and radioiodinated protein A. Anal Biochem 1981; 112: 195-203.

9. Chiu DC, Norton WT, Fields KL. The cytoskeleton of primary astrocytes in culture contains actin, glial fibrillary acidic protein and the fibroblast-type filament protein, vimentin. J Neurochem 1981; 37: 147-155.

10. Ferrari S, Battini R, Kaczmarek $L$, et al. Coding sequence and growth regulation of the human vimentin gene. Mol Cell Biol 1986; 11: 3614-3620.

11. Mork SJ, May EE, Papasozomenos SCH, et al. Characteristics of human medulloblastoma cell line TE 671 under different growth conditions in vitro: a morphological and immunohistochemical study. Neuropathol Appl Neurobiol 1986; 12: 277-289.

12. Bonnin JM, Rubinstein LJ. Immunohistochemistry of central nervous system tumors. J Neurosurg 1984; 60: 1121-1133. 